\title{
GIANT SUBMENTAL HEMANGIOMA: A RARE NECK MASS
}

Arvinder Singh ${ }^{1}$, Manjeet Kaur ${ }^{2}$, Sohan Singh ${ }^{3}$, Ramesh Chander ${ }^{4}$, Suman Bhagat ${ }^{5}$

\section{HOW TO CITE THIS ARTICLE:}

Arvinder Singh, Manjeet Kaur, Sohan Singh, Ramesh Chander, Suman Bhagat. "Giant submental hemangioma: a rare neck mass". Journal of Evolution of Medical and Dental Sciences 2013; Vol. 2, Issue 48, December 02; Page: 9415-9418.

ABSTRACT: A large non symptomatic soft swelling in the submental area are usually due to thyroglossal duct cyst, sublingual dermoid cyst, giant ranula and cystic hygroma. Here we present a case of a rare giant submental hemangioma with multiple phleboliths in the floor of the mouth presenting as a submental swelling. We report a case of 14 years old male who presented with the mass in the submental region that had been gradually growing over period of several years.

KEYWORDS: Giant Submental Hemangioma, Phleboliths, Imaging

INTRODUCTION: Hemangioma is a relatively common lesion in the head and neck region. Blood flow changes in hemangioma result in formation of thrombus and phleboliths ${ }^{6}$. Phlebolith formation reported as a characteristic feature of hemangioma. Although hemangioma is a relatively common in the head and neck region, rarely it is associated with phlebolith in this region.

Hemangioma with phlebolith has been reported in parotid and submandibular glands, mentalis muscle and buccal regions. The clinical information regarding hemangioma with phlebolith in the floor of the mouth is scanty and rare presentation.

CASE REPORT: A 14 years old male presented with a large submental swelling, which had been present for last 2 years and had gradually increased in size without any pain. Clinical examination showed a painless and soft swelling of the submental region [Figure. 1]. On palpation, the mass felt like a spongy tissue with hard structures within it which gave gritty feel like that of a "bag of marbles". Skin over swelling was normal and local temperature was not raised and there was no bruit. The complete blood count, electrolytes, random blood sugar and kidney functions were within normal limits.

Plain $\mathrm{X}$ ray AP and lateral views of the swelling was done which showed a large soft tissue density lesion with multiple well defined round to oval calcified lesions in it [Figure.2].

Sonography of this mass showed a large heterogeneous mass with small anechoic cystic areas in it. Low level echoes were seen in few of them suggestive of thrombus. Scattered calcified calculi with dense posterior acoustic shadowing was present [Figure. 3]. The color doppler ultrasonography revealed very sluggish blood flow in this region.

Painless soft tissue submental mass,anechoic structures with mobile calcified lesions giving 'bag of marble' appearance,the provisional diagnosis of hemangioma with phleboliths was made.

The surgery was performed under general anesthesia and several hard bodies were seen within the mass suggesting multiple phleboliths. Because we found thrombus, phleboliths in hemangioma, we diagnosed this case as cavernous hemangioma with phleboliths in the floor of the mouth in accordance with preoperative diagnosis. 
DISCUSSION: Hemangioma with phlebolith of the parotid and submandibular glands are frequently seen but hemangioma with phlebolith in the floor of the mouth is rarely entity.

The common causes of large painless submental masses are thyroglossal duct cyst, sialadenitis ${ }^{2}$ sublingual dermoid cyst, amyloidosis, hanging ranula and or cystic hygroma ${ }^{1,6}$.

The diagnosis of hemangioma involving the floor of the mouth is difficult. On plain radiography, calcified lesions such as phleboliths are seen as opacities. However, plain x-rays has difficulty in distinguishing between sialolithiasis and phleboliths as in the case reported by Dempsey and Murley ${ }^{3}$.

Ultrasonography is generally able to indicate the location and extent of the mass. Panoramic radiography showed multiple calcific foci in the region of the right submandibular gland. Nevertheless, the result of its pathology was hemangioma with phleboliths. Therefore, these observations were sufficient to diagnose our case, and actually our preoperative diagnosis was in accordance with pathological diagnosis. Furthermore, Cankaya et $\mathrm{al}^{5}$ reported that neither MRI nor CT was sufficient for diagnosis of hemangioma with phleboliths in the sublingual gland as in the case of McMenamin et al ${ }^{4}$.

In conclusion, hemangioma with phleboliths should be considered in the differential diagnosis of submental swelling. Plain radiography,ultrasound along with color doppler ultrasonography is an important investigation method in the evaluation of lesions localized in the submental areas.

\section{REFERENCES:}

1. Yuh Baba,Yasumasa Katob. Hemangioma with phleboliths in the floor of the mouth presenting as a submental swelling: A Case Report J Med Cases 2011; 2(1):28-30.

2. PS Nagpure, S. Jain, P. Dhole, V. Tyagi, R. Singh, D. Garg. Submandibular gland cavernous hemangioma with phlebolith masquerading as sialadenitis. J MGIMS, 2008; 13(II):56 - 58.

3. Dempsey EF, Murley RS. Vascular malformations simulating salivary disease. Br J Plast Surg 1970;23(1):77-84.

4. McMenamin M, Quinn A, Barry H, Sleeman D, Wilson G, Toner M. Cavernous hemangioma in the submandibular gland masquerading as sialadenitis: case report. Oral Surg Oral Med Oral Pathol Oral Radiol Endod 1997;84(2):146-148.

5. Cankaya H, Unal O, Ugras S, Yuca K, Kiris M. Hemangioma with phleboliths in the sublingual gland:as a cause of submental opacity. Tohoku J Exp Med 2003;199(3):187-191.

6. Sarah J La'Porte, Jaspal K Juttla, Ravi K Lingam. Imaging the floor of the mouth and the sublingual space. RadioGraphics 2011; 31:1215-1230 


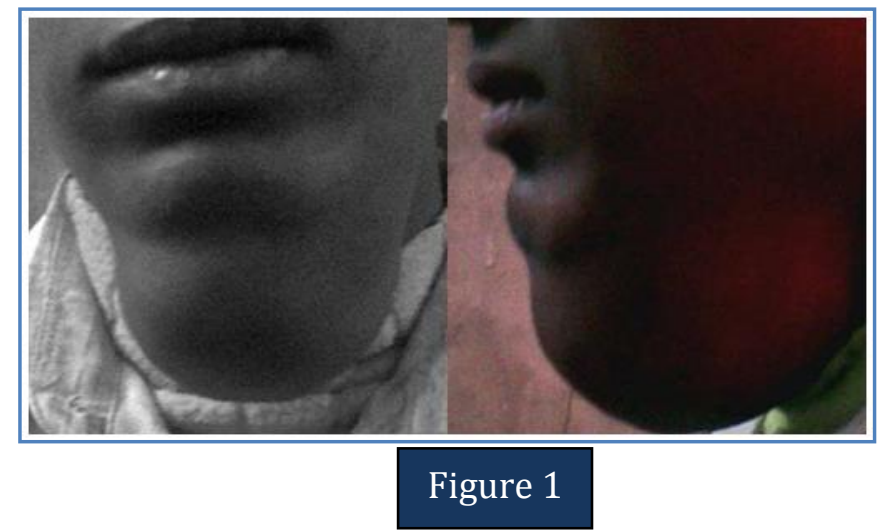

Figure 1: Photograph enface and in profile of a 14 years male with a large well defined mass hanging in submental region. On palpation, there was "bag of marble" appearance.

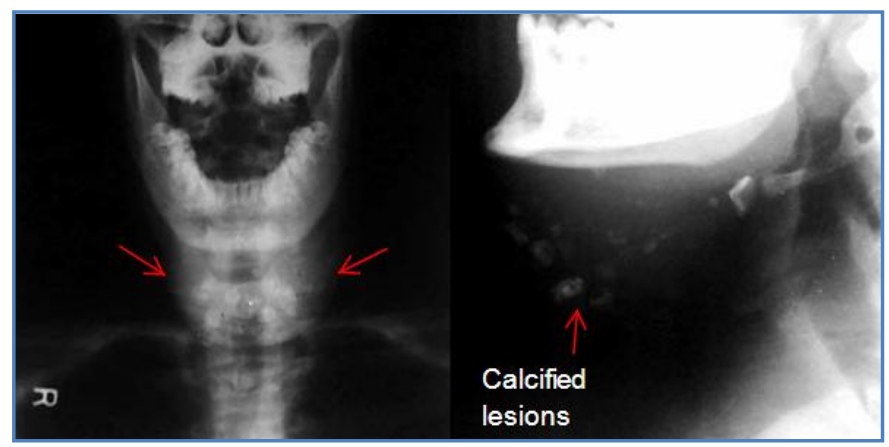

Figure 2

Figure 2: Plain X ray Neck Region AP and Lateral views showing soft tissue density mass in submental region with coarse calcified areas in it. No adjacent bony erosion or destruction was noted.

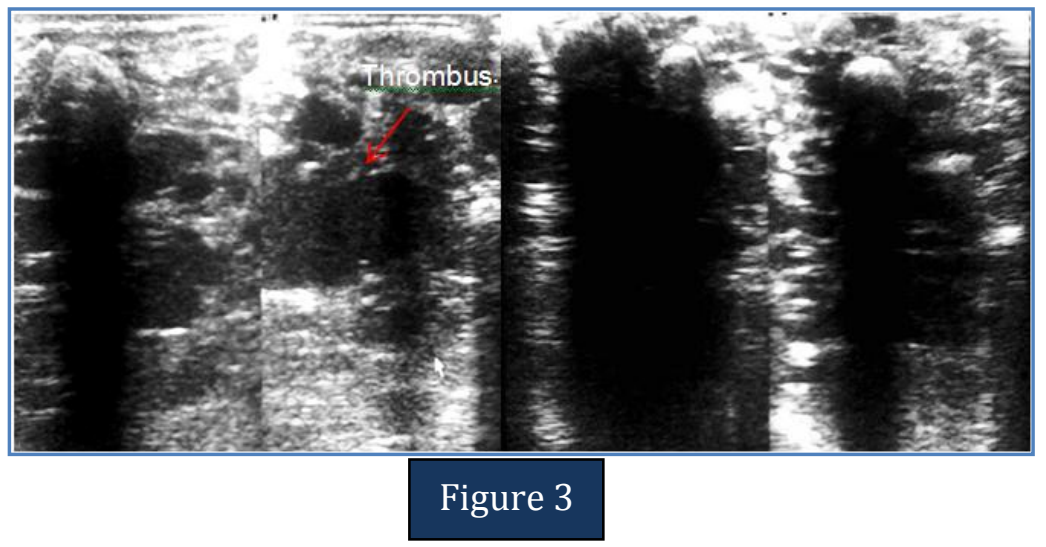

Figure 3-(a) Sonography showing multiple anaechic areas within the mass with soft level internal echoes at few sites suggestive of thrombus (b) Multiple round to oval calcified foci seen within the mass with dense posterior acoustic shadowing suggestive of phleboliths. 


\section{AUTHORS:}

1. Arvinder Singh

2. Manjeet Kaur

3. Sohan Singh

4. Ramesh Chander

5. Suman Bhagat

\section{PARTICULARS OF CONTRIBUTORS:}

1. Associate Professor, Department of Radiodiagnosis, G.M.C., Amritsar.

2. Associate Professor, Department of Physiology, S.G.R.D.I.M.S.A.R, Amritsar.

3. Professor, Department of Radiodiagnosis, G.M.C., Amritsar.
4. Associate Professor, Department of Radiodiagnosis, G.M.C., Amritsar.

5. Senior Resident, Department of Radiodiagnosis, G.M.C., Amritsar.

\section{NAME ADDRESS EMAIL ID OF THE} CORRESPONDING AUTHOR:

Dr. Arvinder Singh, 316-A, Moon Avenue, Street No. 1, Majitha Road, Amritsar, Punjab, India. Email - arvinderdr@rediffmail.com

Date of Submission: 26/10/2013.

Date of Peer Review: 30/10/2013.

Date of Acceptance: 22/11/2013.

Date of Publishing: 28/11/2013. 